\title{
NOÇÕES ARISTOTÉLICAS EM ANAXIMANDRO: ÁPEIRON COMO ELEMENTO PRIMORDIAL E O QUE PENSOU ARISTÓTELES SOBRE O INDEFINIDO
}

\author{
João Batista Freire ${ }^{1}$ \\ Universidade Federal de Uberlândia (UFU) \\ (i) https://orcid.org/0000-0002-1949-7243
}

\begin{abstract}
RESUMO:
Anaximandro de Mileto teria nascido em 610 a.C conforme o testemunho de Hipólito, Aristóteles de Estagira, em 384 a.C. É evidente que vivenciaram períodos distintos na Grécia Arcaica. Contudo, tinham interesses incomuns, a saber; explicar o mundo na esteira da natureza. Anaximandro propôs sua explicação a partir de um elemento indefinido - ' $\alpha \pi \varepsilon i \rho \omega v$. Este trabalho pretende investigar a intenção de Aristóteles ao voltar seu olhar para o elemento primordial anaximandrino, fato assaz curioso, que resulta em quatro citações mencionando o nome de Anaximandro na obra De Caelo, e na Física. Ao contrário de seguir rumo à tradução laboriosa dos fragmentos, o que seria saltar sobre um abismo com limiar escorregadio, pretende-se estabelecer paralelamente e em que se aproximam ou se divergem a cosmologia de Anaximandro e o mundo sublunar e supra lunar abarcados na cosmologia de Aristóteles. Outrossim, nos aproximar da noção de apeíron e éter das respectivas cosmologias desses filósofos.
\end{abstract}

PALAVRAS-CHAVE: Anaximandro; Ápeiron; Aristóteles; Cosmologia; Éter.

\section{Aristotelic notions in Anaximander: apeiron as a primordial element and what Aristotle thought about the indefinite}

\footnotetext{
${ }^{1}$ Mestrando em Filosofia na Universidade Federal de Uberlândia (UFU), Minas Gerais Brasil. E-mail: freireescatos@yahoo.com.br
} 


\begin{abstract}
:
According to the testimony of Hippolytus, Anaximander of Miletus was born in $610 \mathrm{BC}$, whereas Aristotle of Stagira was born in $384 \mathrm{BC}$. It is evident that they experienced different periods in Archaic Greece. However, they had common interests, for instance; the way they explained the world according to the thread of nature. Anaximander proposed his explanation from an undefined element -the ' $\alpha \pi \varepsilon i \rho \omega v$. This work intends to investigate Aristotle's intention when he turned his attention to the anaximandrian primordial element, a rather curious fact, which resulted in four quotations mentioning the name of Anaximander in his work De Caelo, and in Physics. Instead of heading to the laborious translation of the fragments, which would mean jumping over an abyss with a slippery threshold, it is intend to establish a parallel that either approximates or diverges the cosmology of Anaximander and the sublunary sphere, both encompassed in Aristotle's cosmology, as well as trying to approach us to the notion of apeiron and ether, both part of the cosmologies of these philosophers.
\end{abstract}

KEYWORDS: Anaximander; Ápeíron; Aristotle; Cosmology; Ether.

\title{
Introdução
}

A Grécia Arcaica de Anaximandro e Aristóteles foi berço de consideráveis fatores que somaram indiretamente para uma construção idiossincrática de um sistema filosófico anaximandrino e aristotélico. O primeiro sagra-se pelo impávido esforço de inaugurar uma passagem da narrativa mítica tradicional para a narrativa cosmológica, o que Jean Pierre Vernant (1972, p.74), chamará de "revolução intelectual". No mesmo trilho, conforme William Guthrie (1984, p.54), "substituí-la por soluções intelectuais" "2. Sobre a estreita analogia da Teogonia de Hesíodo e a filosofia de Anaximandro, Vernant cita Francis MacDonald Cornford:

Entre a Teogonia de Hesíodo e a filosofia de um Anaximandro, a análise de Cornford faz aparecer estreitas correspondências. Certamente, enquanto um fala ainda de gerações divinas, o outro já descreve processos naturais; é que o segundo se recusa a jogar com a ambigüidade de termos como phyein e génesis, que significam igualmente engendrar e produzir, nascimento e origem. Durante todo o tempo em que esses diversos sentidos permaneciam confusos, podia-se exprimir o devir em termos de união sexual, dar a razão de um fenômeno nomeando seu pai e

\footnotetext{
2 Tradução nossa. GUTHRIE, W. K. C. Historia de la Filosofía Griega: Los Primeros Presocráticos y los Pitagóricos. Tradução de Alberto Medina González. Madrid: Gredos, 1984, p.54. Texto original: Abandonaron las soluciones mitológicas y las sustituyeron por soluciones intelectuales.
}

Noções aristotélicas em Anaximandro - ápeiron como elemento primordial e o que pensou Aristóteles sobre o indefinido - João Batista Freire 
sua mãe, estabelecendo sua árvore genealógica. (VERNANT, 1972 p.75).

A prosperidade material de Mileto oriunda de seu comércio portuário agregou nesse período grego arcaico amálgama suficiente para uma reflexão cosmológica diferente da mentalidade religiosa. Não apenas isso, parafraseando Aristóteles (Metafísica A 982 b 12), Anaximandro está entre os primeiros filósofos que pela a admiração e perplexidade começaram a filosofar. O segundo, Aristóteles viveu no séc. IV a.C e esteve próximo do pensamento de um dos maiores expoentes helenísticos, a saber; Alexandre Magno. Conforme o relato de Guthrie, (1984, p.27) "o estagirita foi preceptor de Alexandre o Grande e continuou sendo seu amigo durante o período de suas conquistas e morreu um ano após a morte de Alexandre, em 323 a.C". ${ }^{3}$ Por um lado Anaximandro rompia com os ritos cosmogônicos. Por outro lado, Aristóteles desenvolvia seu arguto sistema filosófico na esteira da Physis cooparticipante de outras culturas milenares subjugadas pela Macedônia. Parafraseando Werner Jaeger citado por Guthrie ${ }^{4}$ (1993, p.102), as tendências internas do pensamento do estagirita, são em si mesmo produtos da filosofia existente e o impacto sobre ela de sua própria personalidade e disposição mental. Nesse sentido, parafraseando Guthrie (1984, p.29), à medida que a época helenística avançava o mundo lhe parecia como um órgão, possuindo um centro e uma periferia.

O Anaximandro que conhecemos nas obras ${ }^{5}$ De Caelo 123 B 13, 295 b 10, na Física 118 A 4, 187 a 20, 108 Г 4, 203 b. 7 e 104 A 4, 187 a 12 é um fisiólogo descrito por Aristóteles cujos interesses lhes são próprios ${ }^{6}$. Esse argumento está conforme os testemunhos de Geoffrey Kirk, John Raven e Malcom Schofield (1994 Cap. XV) "Aristóteles prestou aos seus predecessores em filosofia uma atenção mais séria do que Platão. Contudo, os seus juízos são frequentemente deformados pela visão que tinha da filosofia anterior". Esse trabalho não pretende elucidar o sistema filosófico de Anaximandro e de Aristóteles, o que constitui em si mesmo um importante e interessante tema, exigindo por si só um tratado para ser

\footnotetext{
3 Tradução nossa. GUTHRIE, William. Historia de la Filosofía Griega: Los Primeros Presocráticos y los Pitagóricos. Tradução de Alberto Medina González. Madrid: Gredos, 1984, p.27. Texto original: Aristóteles fue preceptor de Alejandro Magno, continuó siendo su amigo durante El período de sus conquistas y murió um ano después de la muerte de Alejandro, em el 323.

4 GUTHRIE, William. Historia de la Filosofía Griega Volume VI: Introducción a Aristóteles. Tradução de Alberto Medina González. Madrid: Gredos, 1993, p.102. No intróito do capítulo $\mathrm{V}$ cita o helenista Werner Jaeger comentando sobre A mente de Aristóteles.

${ }^{5}$ Aristóteles também se refere a Anaximandro indiretamente em outras obras.

${ }^{6}$ COUPRIE, Dirk. Heaven and Earth in Ancient Greek Cosmology: From Thales to Heraclides Ponticus. New York: Springer Science Business Media, 2011, p.91. Nesta obra, Dirk nos adverte sobre as fontes de Anaximandro que chegaram até nós sob o prisma aristotélico.
}

Noções aristotélicas em Anaximandro - ápeiron como elemento primordial e o que pensou Aristóteles sobre o indefinido - João Batista Freire 
abordado, mas antes $\mathrm{o}$ de apresentar as noções aristotélicas em Anaximandro: ápeiron como elemento primordial $e$ o que pensou Aristóteles sobre o indefinido. Igualmente, não será proposta qualquer tese inovadora. Todavia, para aqueles cujos interesses voltam-se para os primeiros sábios, esta investigação apontará rumo aos trilhos da Filosofia Pré-socrática.

\section{A cosmogonia e cosmologia de Anaximandro}

Explicar o mundo foi um dos esforços mentais notáveis de Anaximandro. Imaginar uma civilização que diante do sol, o concebe como um deus, e um de seus concidadãos retirar o relâmpago das mãos de Zeus e devolvê-lo à natureza como um fenômeno, conforme o testemunho de Hipólito citado por Kirk, (1994, p.138), dizendo que "o relâmpago originase sempre que o vento se desencadeia e fende as nuvens", logrou-lhe uma explicação científica de acordo com Francis Cornford (2005, p.17). O interesse pela astronomia justifica colocar o filósofo milésio ao lado de Aristóteles que ao seu modo também atentou para essa ciência. A organização do mundo para Anaximandro requeria também a construção de um mapa, o que demonstrou seu interesse pela geografia conforme citado por Kirk, Raven e Schofield:

Agatémero disse que Anaximandro de Mileto, discípulo de Tales, foi o primeiro que ousou desenhar o mundo habitado numa tábua; depois dele, Hecateu de Mileto, homem muito viajado, aperfeiçoou o mapa, por forma que a obra se tornou uma fonte de admiração (KIRK; RAVEN; SCHOFIELD, 1994, p.103).

As abstrações geográficas de Anaximandro somadas às suas viagens deram-lhe um deslocamento visual da terra, que antes, era privilégio apenas dos deuses. Essa interpretação conjectural não pretende se petrificar. De acordo com $\operatorname{Dirk}^{7}$ (2011, p.91), "quaisquer reconstruções dos argumentos usados pelo milésio devem permanecer conjectural, desde que eles sejam manipulados com cuidado".

Qual é a natureza da substância originadora? Por que disse

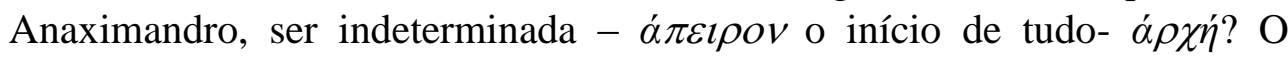
primitivo sistema anaximandrino apontava para uma investigação do que chamará Cornford (1989, p.259) "de uma substância permanente ou

\footnotetext{
${ }^{7}$ Tradução nossa. COUPRIE, Dirk. Heaven and Earth in Ancient Greek Cosmology: From Thales to Heraclides Ponticus. New York: Springer Science Business Media, 2011, p.91Texto original: Therefore, any reconstruction of the arguments used by the Milesian must remain conjectural. Nevertheless, the data, provided they are handled with care, allow us to catch glimpses of what the arguments of Anaximander must have looked like.
}

Noções aristotélicas em Anaximandro - ápeiron como elemento primordial e o que pensou Aristóteles sobre o indefinido - João Batista Freire 
natureza das coisas ${ }^{8}$. . A razão nesses termos não poderia lançar alicerces objetivos fundamentados nos elementos materiais conforme a versão do relato de Teofrasto, discípulo de Aristóteles. De acordo com Kirk, Raven e Schofield (1994, p.105) "parte da informação fornecida por Teofrasto sobre a matéria originadora de Anaximandro encontra-se em Simplício". Diz o excerto:

Entre os que admitem um só princípio móvel e infinito, Anaximandro de Mileto, filho de Praxíades, sucessor e discípulo de Tales, disse que o princípio e elemento das coisas que existem era o ápeiron, [indefinido ou infinito], tendo sido ele o primeiro a introduzir este nome do princípio material. Diz ele que tal princípio não é nem água nem qualquer outro dos chamados elementos, mas uma outra natureza ápeiron, de que provém todos os céus e os mundos neles contidos (KIRK; RAVEN; SCHOFIELD,1994, p.105-106).

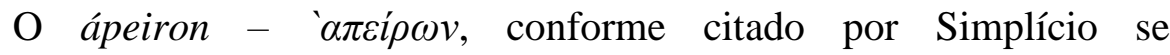
caracterizava como substância primária ilimitada, diferenciando-se do quente, do frio, do úmido e do seco. Compreende-se que, na cosmogonia anaximandrina a substância primária do universo não poderia ser coisas que se opõem mutuamente, como um modo se ser extremo, um em relação ao outro. A questão torna-se objeto de uma investigação pormenorizada e carente de um espírito não anacrônico ao passo que, como diz Cornford (1989, p.289-290), "o quente, o frio, o calor e umidade, não seriam para Anaximandro simples qualidades, mas antes, coisas", potências primeiras. É nesse sentido que Anaximandro rompe com seu mestre. Os primeiros elementos possuem limites peras - $\pi \dot{\varepsilon} \rho \alpha \varsigma$, ao passo que o imperceptível ápeiron - $\alpha$ alfa privativo significa ausência de limites. Seguindo na esteira de Guthrie (1987, p.26) "se tudo tivesse sido originariamente água ou umidade, como propunha Tales, nunca teria existido calor ou fogo, pois a água não gera fogo, pelo contrário, destrói-o".

Aristóteles sentiu-se atraído pelo assunto do milésio, e prestou consideráveis argumentações em torno do ápeiron. O estagirita em sua obra Sobre o Céu (DK 295 b 10) conforme a tradução de Kirk, Raven e Schofield $\left(1994\right.$, p.134) ${ }^{9}$ cita Anaximandro dizendo que "ele está entre os antigos que afirmam que a Terra se mantém imóvel devido ao seu equilíbrio". Em seguida, Aristóteles argumenta desfavoravelmente ao argumento do milésio. Cada uma das coisas, sejam aquelas pertencentes à região celeste ou à região terrestre, tem segundo Aristóteles (Sobre o Céu II. 295b), seu "lugar

\footnotetext{
${ }^{8}$ Cornford pontua que essa natureza é a $\phi v ́ \sigma \iota \varsigma$,

9 Texto grego segundo a obra de Hermann Diels, Die Fragmente der Vorsokratiker (edições $5^{a}$ e posteriores, Berlim, 1934-54, editados por Walther Kranz). 123 Aristóteles

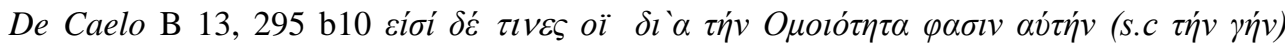
$\mu \varepsilon \dot{v \varepsilon \imath v, ~ \omega ́ \sigma \pi \varepsilon \rho ~ \tau \omega v ~ \alpha \rho \chi \alpha i \omega v ~ ' A v \alpha \xi i ́ \mu \alpha v \delta \rho o \varsigma . ~}$
}

Noções aristotélicas em Anaximandro - ápeiron como elemento primordial e o que pensou Aristóteles sobre o indefinido - João Batista Freire 
natural" e seu "movimento natural" para este lugar. A Terra está em repouso em seu lugar natural, o centro do universo. Logo, o movimento de qualquer outro objeto terreno será retilíneo para baixo. Ao expor seu sistema, Aristóteles de alguma forma torna o sistema anaximandrino ainda mais evidente. Mas em que sentido essa conjectura é possível? O limite peras -

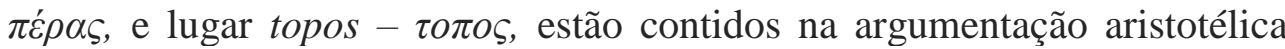
cujo cerne é a "finitude do lugar e do corpo nele contido" (Sobre o Céu, 1, 273 a 15). Kirk, Raven e Schofield (1994, p.108), com prudência levantam a hipótese que Aristóteles teria pensado o ápeiron de Anaximandro como algo espacialmente infinito. Os autores conjecturam sobre essa problemática tomando como fundamento o fragmento 102 (Aristóteles, Físi. Г 4203 a 16), "todos os físicos fazem do infinito uma propriedade de outra natureza inerente aos chamados elementos, tais como a água ou o ar ou o seu intermediário". Entretanto, a tese aristotélica se enfraquece quando os escritos de Teofrasto são considerados na citação de Simplício (Fís. 24, 13; DK 12 A 9), que em paráfrase diz que o ilimitado não se refere aos elementos materiais, de modo que se sustentará o ápeiron, como espacialmente indefinido ${ }^{10}$.

\section{Aspectos da cosmologia aristotélica e nuanças anaximandrianas}

No centro do Universo repousa imóvel a esfera Terra. O Universo aristotélico é dividido em duas regiões nitidamente distintas: a celeste e a terrestre. Os elementos água, terra, ar, e fogo são constituintes corruptíveis da região sublunar, cujos movimentos são retilíneos. Entretanto, a região supralunar abarca os corpos celestes incorruptíveis legitimados pelo movimento circular. Disse o estagirita:

Com efeito, o perfeito é por natureza anterior ao imperfeito; ora, o círculo entra na classe das coisas perfeitas, enquanto que a linha reta não é, em nenhum caso, perfeita: não são perfeitas, com efeito, nem a linha reta infinita - pois ela deveria ter limite e fim -, nem qualquer linha reta finita - pois todas têm alguma coisa para fora, pois que se pode prolongar qualquer linha reta (ARISTÓTELES, 269 A 19-25) ${ }^{11}$.

É possível hipoteticamente conjecturar nuanças na cosmogonia de Aristóteles com o arguto sistema cosmogônico de Anaximandro. O ápeiron

\footnotetext{
${ }^{10}$ O helenista Francis Cornford coaduna com o pensamento de Simplício. Cornford entende que ápeiron, também significa espacialmente indefinido. CORNFORD, Francis. Principium Sapientiae: As Origens do Pensamento Filosófico Grego. Tradução de Maria Manuela Rocheta dos Santos. Prefácio de W. K. C. Guthrie. $3^{\mathrm{a}}$ ed. Lisboa: Fundação Calouste Gulbenkian, 1989, p.281-289.

${ }^{11}$ Tradução nossa. ARISTOTE. Traité Du Ciel. Traduction par Catherine Dalimier et Pierre Pellegrin. Introduction par Pierre Pellegrin. Ed. No FG103601. Manchecourt: Éditions Flammarion, 2004, p.79. (269 A 19-25).
}

Noções aristotélicas em Anaximandro - ápeiron como elemento primordial e o que pensou Aristóteles sobre o indefinido - João Batista Freire 
como elemento arquétipo para a physis, não excluiu a existência dos quatro elementos, senão no sentido de fundamento original, ou seja, como arché ' $\alpha \rho \chi \eta ்$. Igualmente, Aristóteles está de acordo com a constituição do mundo terrestre oriunda dos quatro elementos. Contudo, os descartam no que tange ao mundo celeste. Para tanto, Aristóteles recorre a um quinto elemento da esteira dos antigos, sobretudo Anaxágoras de Clazómenas ${ }^{12}$, a saber; o aither-aíté $\alpha$. Conforme o fragmento 491 (DK):

Parece que o nome do primeiro corpo tem sido transmitido até os nossos dias desde o tempo dos antigos que alimentavam concepções idênticas às nossas [...] eles acreditavam que o primeiro corpo era algo diferente da terra, do fogo, do ar e da água, e denominaram éter à região mais alta, e lhes deram este nome porque 'ocorre sempre' na eternidade do tempo. É que Anaxágoras fala de aither em vez de fogo. (ARISTÓTELES, 270 в 16-24) ${ }^{13}$

Quando Aristóteles recorre aos antigos conforme citado, abre-se um precedente assaz curioso. Hipoteticamente, o aither de Aristóteles em algum momento, lembra o ápeiron de Anaximandro. Sobretudo, por não ser nenhum dos quatro elementos, e por se aproximar da noção de divino, conforme o fragmento 108 DK (ARISTÓTELES, Fís. $\Gamma$ 4, 203 b7) que diz "e é isto o divino, por ser imortal e indestrutível". E ainda, parafraseando Aristóteles (Sobre o Céu, B1, 284 A11), existe um ser imortal e divino que está em extrema rotação circular, os antigos ${ }^{14}$ atribuíram aos deuses o céu e a região superior como único lugar imortal.

\section{Conclusão}

Anaximandro e Aristóteles efetivamente marcaram suas distintas épocas. Sobretudo, por não deixarem empalidecer a máxima filosófica, a

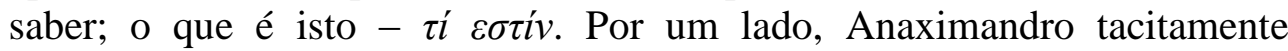

\footnotetext{
${ }^{12}$ Kirk, Raven e Schofield comentam Anaxágoras: "Primeiro o ar, que nesta fase é o oposto do aither, solidifica-se em nuvens; das nuvens vem a água; da água vem a terra; e finalmente da terra solidificam-se as pedras". KIRK, Geoffrey; RAVEN, John; SCHOFIELD, Malcom. Os Filósofos Pré-socráticos: História Crítica com Selecçao de Textos. Tradução de Carlos Alberto Louro Fonseca. $4^{\mathrm{a}}$ ed. Lisboa: Fundação Calouste Gulbenkian, 1994, p.394.

${ }^{13}$ Tradução nossa. ARISTOTE. Traité Du Ciel. Traduction par Catherine Dalimier et Pierre Pellegrin. Introduction par Pierre Pellegrin. Ed. No FG103601. Manchecourt: Éditions Flammarion, 2004, p.89. (270 в 16-24).

${ }^{14}$ Kirk, Raven e Schofield comentam sobre a teologia Órfica aludindo ao Aither "Este Cronos, que não envelhece e cujos desígnios são imperecíveis, criou o Aither e um enorme e prodigioso abismo aqui e além". KIRK, Geoffrey; RAVEN, John; SCHOFIELD, Malcom. Os Filósofos Pré-socráticos: História Crítica com Selecçao de Textos. Tradução de Carlos Alberto Louro Fonseca. $4^{a}$ ed. Lisboa: Fundação Calouste Gulbenkian, 1994, p.18-19.
}

Noções aristotélicas em Anaximandro - ápeiron como elemento primordial e o que pensou Aristóteles sobre o indefinido - João Batista Freire 
direcionava suas investigações em torno da physis, o que posteriormente para Aristóteles serão investigações paliativas. Contudo, o pensamento aristotélico, embora aos seus moldes ${ }^{15}$, sobre o indeterminado de Anaximandro, não desvigorou o legado do milésio, de forma que sua cosmogonia e cosmologia não sejam meritórias. Ambos preocuparam-se com o elemento primordial da natureza, fato assaz semelhante, por não perguntarem sobre essas coisas ao sacerdote ou ao vidente ${ }^{16}$. Nesses termos, é prudente posicionar-se contra uma hermenêutica que rega o solo da oposição Mithos/Logos. Dois Filósofos, duas mentes cujo espanto gerado pela natureza tornou-se seu apanágio. Certamente o especialista desaprovará algumas afirmativas e a omissão de outras. Entretanto, o teor das relações desses dois divisores de água do filosofar, a saber; um da aurora filosófica jônica, o outro da filosofia em seu apogeu clássico, não pretendeu levar seus argutos esquemas de compreensão cosmológica para um campo especulativo. Todavia, pretendeu-se elucidar a imprescindível leitura aristotélica para os investigadores do primevo pensamento de Anaximandro.

\section{Referências}

ALlAN, D. J. A Filosofia de Aristóteles. Tradução de Rui Gonçalo Amado. $2^{a}$ ed. Lisboa: Editorial Presença LTDA, 1970.

ARISTÓTELES. Física. Traducción y introducción de Guillermo R. de Echandía. Madri: Editorial Gredos, S. A. 1995.

Metafísica. Prefácio de Sir David Ross. Tradução de Leonel Vallandro. Ed. 2143 A. Porto Alegre: Globo S. A. 1969.

Traité Du Ciel. Traduction par Catherine Dalimier et Pierre Pellegrin. Introduction par Pierre Pellegrin. Ed. $\mathrm{N}^{\mathbf{0}}$ FG103601. Manchecourt: Éditions Flammarion, 2004.

CORNFORD, Francis. Antes e Depois de Sócrates. Tradução de Walter Lellis Siqueira. São Paulo: Martins Fontes, $1^{\text {a }}$ Ed. 2005.

Principium Sapientiae: As Origens do Pensamento Filosófico Grego. Tradução de Maria Manuela Rocheta dos Santos. Prefácio de W. K. C. Guthrie. $3^{\mathrm{a}}$ ed. Lisboa: Fundação Calouste Gulbenkian, 1989.

\footnotetext{
${ }^{15}$ Aqui, "moldes", se referem ao sistema próprio de Aristóteles, conforme citado na nota de rodapé $n^{\circ} 6$.

${ }^{16}$ Em referência a Anaximandro, isso não significa oposição Mithos/Logos. Conforme o platonista Rubens Garcia Nunes Sobrinho, o mito passa a ser filosófico e a filosofia passa a empregar uma modalidade própria de discursividade consonante com as categorias do pensamento argumentativo. "O mito faz remissão aos argumentos racionais e, mediantes suas figurações, constitui um modelo visualizável que enseja a inteligência das concepções forjadas pela argumentação". SOBRINHO, Rubens Garcia Nunes. Platão e a imortalidade: mito e argumentação no Fédon. $1^{\mathrm{a}}$ ed. Uberlânida: EDUFU, 2007, p.62.
} 
COUPRIE, Dirk. Heaven and Earth in Ancient Greek Cosmology: From Thales to Heraclides Ponticus. New York: Springer Science Business Media, 2011.

GUTHRIE, William. Historia de la Filosofía Griega: Los Primeros Presocráticos y los Pitagóricos. Tradução de Alberto Medina González. Madrid: Gredos, 1984.

Historia de la Filosofía Griega Volume VI: Introducción a Aristóteles. Tradução de Alberto Medina González. Madrid: Gredos, 1993.

Os Filósofos Gregos: De Tales a Aristóteles. Tradução de Maria José Vaz Pinto. Lisboa: Editorial Presença LTDA, 1987.

KIRK, Geoffrey; RAVEN, John; SCHOFIELD, Malcom. Os Filósofos Présocráticos: História Crítica com Selecçao de Textos: As fontes da Filosofia Pré-socrática. Tradução de Carlos Alberto Louro Fonseca. $4^{\mathrm{a}}$ ed. Lisboa: Fundação Calouste Gulbenkian, 1994, Capítulo XV.

SOBRINHO, Rubens Garcia Nunes. Platão e a imortalidade: mito e argumentação no Fédon. $1^{\mathrm{a}}$ ed. Uberlânida: EDUFU, 2007.

VERNANT, Jean-Pierre. As origens do Pensamento Grego. Tradução de Ísis Lana Borges. São Paulo: Difusão Européia do Livro, 1972.

\section{Referências secundárias:}

ARISTÓTELES. Acerca de la Generación y la Corrupción: Tratados Breves de História Natural. Introducciones, traducciones y notas por Ernesto la Croce y Alberto Bernabé Pajares. Madrid: Editorial Gredos, S. A. 1987. COLLI, Giorgio. El Nacimiento de la Filosofía. Traducción: Carlos Manzano. Barcelona: Tusquets, 1977.

JAEGER, Werner. Paidéia: A Formação do Homem Grego. Tradução de A. M. Parreira São Paulo: Martins Fontes, 2001.

LEGRAND, Gérard. Os Pré-socráticos. Tradução de Lucy Magalhães. Rio de janeiro: Jorge Zahar Editor, 1991.

REALE, Giovanni; ANTISERI, Dario. História da Filosofia: Antiguidade e Idade Média: Aristóteles e o Perípatos. Vol. I. São Paulo: Paulus, 1990, p.173-197.

ROVELLI, Carlo. Anaximandro de Mileto: O Nascimento do Pensamento Científico. Tradução de Fernando Soares Moreira. São Paulo: Edições Loyola, 2013.

SPINELLI, Miguel. Filósofos Pré-socráticos: Primeiros Mestres da Filosofia e da Ciência Grega. Porto Alegre: EDIPUCRS, 1998.

VERNANT, Jean-Pierre. Mito e Religião na Grécia Antiga. Tradução de Joana Angélica D’Avila Melo. $1^{\text {a }}$ ed. São Paulo: Martins Fontes, 2006. 